DOI: 10.25557/0031-2991.2021.03.56-63

(с) Охремчук Л.В., Семинский И.Ж., 2021

УДК 616-092.9:615.099]:615.272

Охремчук Л.В., Семинский И.Ж.

Протекторный эффект адеметионина, цитофлавина и дигидрокверцетина у крыс, подвергнутых токсическому влиянию вальпроата натрия

ФГБОУ ВО «Иркутский государственный медицинский университет» Минздрава России, 664003, Иркутск, Россия, ул. Красного Восстания, д. 1

Введение. Вальпроат натрия влияет на метаболизм гамма-аминомасляной кислоты, предотвращая развитие эпилептических приступов. Многие метаболиты вальпроата натрия потенцируют его клинический эффект, однако, именно они могут приводить к развитию хронической интоксикации с поражением печени.

Цель - оценка протекторного эффекта адеметионина (гептрала), цитофлавина и дигидрокверцетина у крыс, подвергнутых токсическому влиянию вальпроата натрия (депакина).

Методика. Животным контрольной группы вводили вальпроат натрия в токсической дозе 600 мг/кг интрагастрально 1 раз в день в течение 28 сут. Крысам опытных групп вводили вальпроат натрия в той же дозе с одновременным введением адеметионина, цитофлавина или дигидрокверцетина. Животные выводились из эксперимента на 7-, 14-, 21- и 28-е сут. В гомогенате печени определяли стандартными спектрофотометрическими методами концентрацию диеновых конъюгатов, малонового диальдегида, восстановленного глутатиона и активность ферментов метаболизма глутатиона: глутатионредуктазы, глутатионпероксидазы и глутатионтрансферазы.

Результаты. При токсическом воздействии вальпроата натрия в ткани печени развивались процессы гиперпероксидации липидов, которые подтверждались значительным повышением уровня диеновых конъюгатов и малонового диальдегида. Концентрация глутатиона снижалась начиная с 14-х сут эксперимента. Активность глутатионредуктазы повышалась к 14-м сут, а затем к 28-м сут практически достигала значений интактных животных. Активность глутатионтрансферазы начинала снижаться с 14-х сут и сохранялась низкой до конца исследования. Активность глутатионпероксидазы повышалась с 14-х сут эксперимента, достигая максимума к 28-м сут. Протекторный эффект адеметионина при токсическом воздействии вальпроата натрия выражался в снижении содержания диеновых конъюгатов и малонового диальдегида. Одновременно происходила активация системы глутатиона: повышалась активность глутатионтрансферазы и глутатионредуктазы. Антиокислительное действие цитофлавина проявлялось в основном на 1-й нед эксперимента: концентрация диеновых конъюгатов и малонового диальдегида снижалась, активность глутатионредуктазы и глутатионтрансферазы повышалась. Дигидрокверцетин также оказывал антиокислительное действие: концентрация диеновых конъюгатов и малонового диальдегида снижалась. Активность глутатионредуктазы и глутатионтрансферазы увеличивалась по сравнению с контрольными животными.

Заключение. Вальпроат натрия в токсической дозе приводит к статистически значимому повышению уровня продуктов перекисного окисления липидов и снижению антиокислительной защиты системы глутатиона в печени крыс. Адеметионин, цитофлавин и дигидрокверцетин способствуют восстановлению баланса системы перекисного окисления липидов и антиоксидантной защиты в печени крыс при токсическом влиянии вальпроата натрия. Наиболее перспективным препаратом защиты является адеметионин, так как он наиболее существенно снижает концентрацию диеновых конъюгатов, малонового диальдегид и повышает активность системы глутатиона на протяжении 28 сут эксперимента.

Ключевые слова: протекторный эффект; печень; глутатион; перекисное окисление липидов; вальпроат натрия (депакин); адеметионин (гептрал); цитофлавин, дигидрокверцетин

Для цитирования: Охремчук Л.В., Семинский И.Ж. Протекторный эффект адеметионина, цитофлавина и дигидрокверцетина у крыс, подвергнутых токсическому влиянию вальпроата натрия. Патологическая физиология и экспериментальная терапия. 2021; 65(3): 56-63.

DOI: 10.25557/0031-2991.2021.03.56-63

Участие авторов: проведение эксперимента, сбор и обработка материала, статистическая обработка результатов, написание текста - Охремчук Л.В.; концепция и дизайн исследования, статистическая обработка результатов, написание текста, редактирование - Семинский И.Ж.

Для корреспонденции: Охремчук Людмила Васильевна, e-mail: doktor777030371@gmail.com 
Финансирование. Исследование не имело спонсорской поддержки. Конфликт интересов. Авторы заявляют об отсутствии конфликта интересов.

Поступила 05.092020

Принята к печати 30.06.2021

Опубликована 30.09.2021

Okhremchuk L.V., Seminskiy I.Zh.

\title{
Protective effects of ademetionine, cytoflavin, and dihydroquercetin in the liver of rats exposed to toxic effects of valproate sodium
}

\author{
Irkutsk State Medical University, \\ Krasnogo Vosstaniya St. 1, Irkutsk 664003, Russian Federation
}

Background. Sodium valproate affects metabolism of gamma-aminobutyric acid to prevent the development of epileptic seizures. Many valproic acid metabolites potentiate its clinical effect; however, specifically these metabolites may result in chronic intoxication with liver damage.

Aim: To evaluate the protective effect of ademetionine (Heptral), cytoflavin, and dihydroquircetin in rats exposed to the toxic action of sodium valproate (Depakene).

Methods. Animals of the control group were administered valproate sodium at a toxic dose of $600 \mathrm{mg} / \mathrm{kg}$, intragastrically. Rats of the experimental group were administered valproate sodium at a dose of $600 \mathrm{mg} / \mathrm{kg}$ with simultaneous administration of ademetionine, cytoflavin and dihydroquercetin. The duration of drug administration in all groups was 7 days, 14 days, 21 days, or 28 days. The contents of diene conjugates, malonic dialdehyde, reduced glutathione, and the activity of glutathione reductase, glutathione peroxidase, and glutathione transferase were measured in liver homogenates with standard spectrophotometric methods. Results. Under the toxic effects of valproate sodium in liver tissue, a significant increase in the contents of diene conjugates and malonic dialdehyde was found. The glutathione concentration decreased starting from day 14 of the experiment. The glutathione reductase activity increased by day 14 and practically reached the values of intact animals by day 28 . The glutathione transferase activity began decreasing on day 14 and remained low until the end of study. The glutathione peroxidase activity increased starting from day 14 and reached maximum by day 28. The protective effect of ademetionine was manifested by a decrease in the contents of diene conjugates and malonic dialdehyde. There was a simultaneous activation of the glutathione system evident as increased activities of glutathione transferase and glutathione reductase. An antioxidant effect of cytoflavin was manifested mainly at the $1^{\text {st }} w \mathrm{k}$ of the experiment. The concentration of diene conjugates and malonic dialdehyde decreased, the activity of glutathione reductase increased, and the activity of glutathione transferase increased. Dihydroquercetin also had an antioxidant effect since the concentration of diene conjugates and malonic dialdehyde decreased. The activity of glutathione reductase and glutathione transferase increased.

Conclusion. Sodium valproate significantly increased concentrations of lipid peroxidation products and impaired the glutathione antioxidant defense in the rat liver. Ademetionine, cytoflavin and dihydroquercetin help to restore the balance of lipid peroxidation and antioxidant protection in the rat liver during the toxic effects of valproate sodium. The most effective drug was ademetionine, since within 28 days, it significantly decreased the concentration of diene conjugates and malonic dialdehyde, and it increased the activity of the glutathione system.

Keywords: protective effect; liver; glutathione; lipid peroxidation; sodium valproate (Depakene); ademetionine (Heptral); cytoflavin; dihydroquercetin

For citation: Okhremchuk L.V., Seminskiy I.Zh. Protective effect of ademetionine, cytoflavinum and dihydroquercetin in the liver of rats exposed to toxic effects of valproate sodium. Patologicheskaya Fiziologiyai Eksperimental naya terapiya. (Pathological Physiology and Experimental Therapy, Russian Journal). 2021; 65(3): 56-63. (in Russian).

DOI: 10.25557/0031-2991.2021.03.56-63

Contribution: conducting the experiment, collecting and processing the material, statistical processing of the results, writing the text Okhremchuk L.V.; the concept and design of the study, statistical processing of the results, writing the text, editing - Seminsky I.Zh.

For correspondence: Lyudmila V. Okhremchuk, Candidate of Medical Sciences, Irkutsk State Medical University, 1 Krasnogo Vosstaniya Str., Irkutsk 664003, Russian Federation, e-mail:doktor777030371@gmail.com

Acknowledgments. The study had no sponsorship.

Conflict of interest. The authors declare no conflict of interest.

Information about the authors:

Okhremchuk L.V., https://orcid.org/0000-0002-4371-6039

Seminskiy I.Zh., https://orcid.org/0000-0002-5982-3875

Received: 05.09.2020

Accepted: 30.06 .2021

Published: 30.09 .2021 
За последнее десятилетие возросла доля токсического поражения печени лекарственными средствами (ЛС). К настоящему времени подтверждена роль более тысячи ЛС, пищевых добавок и растительных продуктов в развитии лекарственно индуцированных поражений печени и этот перечень продолжает увеличиваться с каждым годом [1-3]. В качестве одного из провоцирующих повреждение печени препаратов может явиться вальпроат натрия (ВН). ВН широко используется в эпилептологии, т. к. он влияет на метаболизм гамма-аминомасляной кислоты (ГАМК), предотвращая развитие эпилептических приступов и когнитивного дефицита, что достигается длительным проведением лекарственной терапии в среднем в течение 2-5 лет и более, или пожизненно [4]. Многие метаболиты ВН - биологически активные вещества, которые потенцируют его клинический эффект, однако, именно они могут приводить к хронической интоксикации с развитием поражения печени [5]. Частота нежелательных побочных реакций (НПР) на фоне противоэпилептической терапии варьирует от 7 до $25 \%$ $[4,5]$, может достигать $68,3 \%$ [6]. Частота развития гепатита наблюдается у 1:20 000 человек среди всех леченых; для детей моложе 2 лет, получающих политерапию, риск возрастает до 1:600-1:800 и снижается по мере взросления [2, 4-6].

В предыдущих наших исследованиях на животных в установке «открытое поле» и «приподнятый крестообразный лабиринт» показано, что ВН в дозе 600 мг/ кг обладает анксиогенными (тревожными) свойствами. Это проявляется подавлением горизонтальной активности; снижением вертикальной активности; подавлением исследовательской активности (норковый рефлекс) животных и изменением их эмоциональной активности, что свидетельствует о выраженных реакциях тревоги и страха [7]. Учитывая, что в клинической практике при эпилепсии применяется длительная фармакотерапия ВН, изучение закономерности ответной реакции организма на токсическое воздействие препарата представляет несомненный интерес. Подходы к лечению и профилактике токсического эффекта ВН должны включать поиск патогенетических средств, оказывающих комплексное воздействие. По нашему мнению этой задаче в полной мере отвечают S-аденозил-L-метионин (адеметионин), цитофлавин, дигидрокверцетин [8].

Цель исследования - определение содержания диеновых конъюгатов (ДК), малонового диальдегида (МДА), восстановленного глутатиона (GSH) и активности глутатионредуктазы (ГР), глутатионпероксидазы (ГПО), глутатионтрансферазы (ГТ) в печени бес- породных крыс подвергнутых токсическому действию ВН (депакина) и оценка протекторного эффекта адеметионина (гептрала), цитофлавина, дигидрокверцетина.на протяжении 28 суток исследования.

\section{Методика}

Эксперимент проведен на 238 белых беспородных крысах-самцах (масса тела 190-210 г.), которые находились в условиях вивария Федерального государственного бюджетного научного учреждения «Восточно-сибирский институт медико-экологических исследований» (Ангарск). Животные находились в стандартных условиях вивария с естественной сменой светового цикла, имели свободный доступ к пище и воде. Работу с животными проводили в соответствии с «Правилами надлежащей лабораторной практики», утвержденными приказом Министерства здравоохранения РФ № 199н от 1 апреля 2016 г. и Межгосударственными стандартами ГОСТ 33215-2014, ГОСТ 33216-2014 «Руководство по содержанию и уходу за лабораторными животными», соответствующими Европейской конвенции о защите позвоночных животных, используемых в экспериментах и других научных целях (ЕTC № 123, Страсбург, 18 марта 1986 г. с приложением от 15.06.2006). Исследование одобрено Этической комиссией Иркутского государственного медицинского университета, соответствует нормативным требованиям проведения доклинических экспериментальных исследований (протокол № 3 от 06.03.2019).

В соответствии с протоколом исследования все беспородные крысы были распределены на группы: 1-я группа - интактные животные, 2-я - группа сравнения (контрольная) получала противосудорожный препарат ВН (доза 600мг/кг) интрагастрально 1 раз в день в течение 28 сут. Группы 3-, 4- и 5-я - опытные. Животные этих групп получали интрагастрально 1 раз в день ВН (доза 600мг/кг) с одновременным введением адеметионина в растворе (1000 мг/кг внутрибрюшинно) на основе лиофилизата (3-я группа), цитофлавина (100 мг/кг, расчет по сукцинату) в/брюшинно (4-я группа) и дигидрокверцетин, субстанцию которого вводили интрагастрально в $1 \%$ растворе крахмального клейстера в дозе 50 мг/кг (5-я группа). Дозу ВН рассчитывали исходя из среднесуточной дозы для человека массой 60 кг, которая составляет $1200-2100$ мг в сутки [9]. Эту дозу мы увеличили на 50\% в пересчете на массу тела животных. Препараты коррекции применяли за 1,5 ч до введения ВН 1 раз в сут ежедневно на протяжении 28 сут в средних терапевтических дозах. Животные выводились из эксперимента через 7, 14, 21 и 28 сут с применением диэтилового эфира. В растворе гомо- 


\section{DOI: 10.25557/0031-2991.2021.03.56-63}

гената печени определяли стандартными спектрофотометрическими методами концентрацию ДК, МДА $[10,11], \mathrm{GSH}$ и активность ферментов метаболизма глутатиона: ГПО, ГР и ГТ [12, 13]. Для анализа полученных данных использовали пакет STATISTICA7,0 Stat-SoftInc, США. При анализе близости распределения данных к нормальному закону использовали визуально-графический метод и критерии согласия Колмогорова-Смирнова с поправкой Лиллиефорса и Шапиро-Уилка. Проверка равенства генеральных дисперсий осуществлялась с помощью критерия Фишера (F-test). При анализе межгрупповых различий для независимых выборок использовали непараметрический критерий Манна-Уитни. Критический уровень значимости принимался равным $5 \%(0,05)$.

\section{Результаты}

Как следует из таблицы $\mathbf{1 ,}$ введение крысам токсической дозы ВН приводит к постепенному увеличению концентрации ДК и МДА в ткани печени в течение всего срока наблюдения. Максимальное значение этих показателей регистрируется на 28-е сут эксперимента. Концентрация CSH незначительно снижается по сравнению с контролем начиная с 7-х сут. Активность ГР максимальна на 14-е сут наблюдения, ГТ незначительно снижается начиная с 14-х сут по сравнению с контрольными животными. Активность ГПО резко возрастает с 7-х до 28-х сут эксперимента. В целом, представленные показатели отражают динамику развития оксидативного стресса в клетках печени, который сопровождается дисбалансом в системе ПОЛAO3 в сторону увеличения продуктов окисления ли- пидов и снижения механизмов предупреждения гиперпероксидации.

В таблице 2 представлены результаты эксперимента по коррекции токсического действия ВН адеметионином. Показано, что одновременное с ВН введение адеметионина приводит к значительному снижению уровня МДА и ДК, небольшому снижению концентрации CSH в ткани печени крыс в течение всего срока наблюдения. Активность ГР и ГТ в целом увеличивается, а ГПО снижается начиная с 14-х сут эксперимента. Полученные результаты свидетельствуют о явном протекторном действии адеметионина, который восстанавливает равновесие в системе ПОЛ-АОЗ в печени крыс, подвергнутых воздействию токсических доз ВН.

В таблице 3 демонстрируются показатели системы ПОЛ-АОЗ в печени животных, которым в качестве препарата коррекции вводили цитофлавин. Установлено, что введение цитофлавина приводит к уменьшению концентрации продуктов пероксидации в ткани печени (уровень МДА и ДК статистически значимо снижен на протяжении времени эксперимента). Наблюдается оптимизация активности ряда ферментов системы глутатиона по сравнению с контрольными животными, то есть цитофлавин может предупреждать сверхактивацию ПОЛ, вызванную токсическим действием ВН.

Таблица 4 демонстрирует результаты эксперимента по влиянию дигидрокверцетина на показатели ПОЛ и системы АОЗ в ткани печени крыс, подвергнутых влиянию токсических доз ВН. Регистрируется снижение уровня МДА и ДК в печени у этой группы животных по сравнению с контролем в те-

таблича 1/Table 1

Концентрации ДК, МДА, GSH и активность ГР, ГТ, ГПО в печени крыс, подвергнутых воздействию ВН, (M $\pm m)$ Concentrations of DC, MDA, and GSH and activities of GR, GT, and GPO in the liver of rats exposed to the toxic effect of SV as compared to intact animals

\begin{tabular}{|c|c|c|c|c|c|}
\hline \multirow[b]{3}{*}{ Показатели } & \multirow{3}{*}{$\begin{array}{c}\text { Группа } 1 \\
\text { интактные } \\
\text { n= } 30\end{array}$} & \multicolumn{4}{|c|}{ Сроки исследования (сутки) } \\
\hline & & 7 сут & 14 сут & 21 сут & 28 сут \\
\hline & & $\begin{array}{c}\text { Группа } 2 \\
\text { контрольные } \\
n=23\end{array}$ & $\begin{array}{c}\text { Группа } 2 \\
\text { контрольные } \\
n=13\end{array}$ & $\begin{array}{c}\text { Группа } 2 \\
\text { контрольные } \\
n=13\end{array}$ & $\begin{array}{c}\text { Группа } 2 \\
\text { контрольные } \\
n=15\end{array}$ \\
\hline ДК, мкмоль/мл & $5,71 \pm 0,34$ & $10,81 \pm 0,33^{* *}$ & $14,91 \pm 0,36^{* *}$ & $17,22 \pm 0,51^{* *}$ & $29,32 \pm 0,52^{* *}$ \\
\hline МДА, мкмоль/мЛ & $5,13 \pm 0,23$ & $8,32 \pm 0,31^{* *}$ & $8,32 \pm 0,20$ ** & $14,51 \pm 0,47^{* *}$ & $17,51 \pm 0,48^{* *}$ \\
\hline GSH, мкмоль/г & $5,42 \pm 0,05$ & $5,41 \pm 0,06$ & $4,51 \pm 0,26^{* *}$ & $4,53 \pm 0,26^{* *}$ & $4,63 \pm 0,19^{* *}$ \\
\hline ГТ, нмоль/мин на 1 мг белка & $307,12 \pm 9,56$ & $308,21 \pm 10,54$ & $223,12 \pm 7,82^{* *}$ & $250,11 \pm 8,03^{* *}$ & $249,23 \pm 5,41^{* *}$ \\
\hline ГПО, нмоль/мин на 1 мг белка & $84,12 \pm 1,49$ & $86,11 \pm 0,98$ & $98,23 \pm 6,83^{* *}$ & $82,11 \pm 5,93$ & $154,21 \pm 7,21^{* *}$ \\
\hline
\end{tabular}

Примечание. ** - статистически значимые различия ( $p \leqslant 0,05)$ между животными, получавшими ВН и интактными.

Note. ${ }^{* *}$ - statistically significant differences $(p \leqslant 0.05)$ between animals treated with sodium valproate and intact ones. 
чение 28 сут наблюдения. Концентрация CSH также незначительно снижена. Активность ферментов глутатиона (ГР, ГПО, ГТ) статистически значимо повышена на протяжении всего периода наблюде- ния по сравнению с контрольными крысами. В целом, имеется тенденция к позитивному влиянию дигидрокверцетина на процесс ПОЛ у крыс, получавших большие дозы ВН.

Таблича 2/Table 2

Концентрации ДК, МДА, GSH и активность ГР, ГТ, ГПО в печени крыс, подвергнутых воздействию ВН и препарата коррекции адеметионина, $(M \pm m)$

Concentrations of DC, MDA, and GSH and activities of GR, GT, and GPO in the liver of rats exposed to the toxic effect of SV and the corrective treatment with ademetionine

\begin{tabular}{|c|c|c|c|c|c|c|c|c|}
\hline \multirow[t]{3}{*}{ ППоказатели } & \multicolumn{8}{|c|}{ Сроки исследования (сутки) } \\
\hline & \multicolumn{2}{|c|}{7 сут } & \multicolumn{2}{|c|}{14 сут } & \multicolumn{2}{|c|}{21 сут } & \multicolumn{2}{|c|}{28 сут } \\
\hline & $\begin{array}{c}\text { Группа 2-я } \\
\text { (контроль) } \\
n=23\end{array}$ & $\begin{array}{c}\text { Группа 3-я } \\
\text { (опыт) } \\
n=14\end{array}$ & $\begin{array}{c}\text { Группа 2-я } \\
\text { (контроль) } \\
n=13\end{array}$ & $\begin{array}{c}\text { Группа } 3 \\
\text { (опыт) } \\
n=12\end{array}$ & $\begin{array}{c}\text { Группа 2-я } \\
\text { (контроль) } \\
n=13\end{array}$ & $\begin{array}{c}\text { Группа } 3 \\
\text { (опыт) } \\
n=13\end{array}$ & $\begin{array}{c}\text { Группа } 2 \\
\text { (контроль } \\
n=15\end{array}$ & $\begin{array}{c}\text { Группа } 3 \\
\text { (опыт) } \\
n=12\end{array}$ \\
\hline ДК, мкмоль/мл & $10,81 \pm 0,33$ & $8,43 \pm 0,18^{*}$ & $14,91 \pm 0,36$ & $10,82 \pm 0,23^{*}$ & $17,22 \pm 0,51$ & $16,73 \pm 0,20$ & $29,32 \pm 0,52$ & $17,32 \pm 0,30 *$ \\
\hline $\begin{array}{l}\text { МДА, } \\
\text { мкмоль/мл }\end{array}$ & $8,32 \pm 0,31$ & $6,52 \pm 0,12 *$ & $8,32 \pm 0,20$ & $5,41 \pm 0,17^{*}$ & $14,51 \pm 0,47$ & $7,12 \pm 0,25^{*}$ & $17,51 \pm 0,48$ & $6,91 \pm 0,30^{*}$ \\
\hline $\begin{array}{l}\text { ГР, нмоль/мин } \\
\text { на } 1 \text { мг белка }\end{array}$ & $17,23 \pm 0,86$ & $26,51 \pm 0,59 *$ & $29,33 \pm 0,65$ & $28,71 \pm 0,47$ & $13,52 \pm 0,57$ & $27,71 \pm 0,25^{*}$ & $15,81 \pm 0,62$ & $27,32 \pm 0,16^{*}$ \\
\hline $\begin{array}{l}\text { ГТ, нмоль/мин } \\
\text { на } 1 \text { мг белка }\end{array}$ & $308,21 \pm 10,54$ & $282,21 \pm 8,64$ & $223,12 \pm 7,82$ & $326,32 \pm 12,8^{*}$ & $250,11 \pm 8,03$ & $320,22 \pm 2,85^{*}$ & $249,23 \pm 5,41$ & $352,13 \pm 7,74 *$ \\
\hline $\begin{array}{l}\text { ГПО, нмоль/м } \\
\text { на } 1 \text { мг белка }\end{array}$ & $86,11 \pm 0,98$ & $91,32 \pm 1,61 *$ & $98,23 \pm 6,83$ & $68,21 \pm 3,29 *$ & $82,11 \pm 5,93$ & $67,32 \pm 1,19^{*}$ & $154,21 \pm 7,21$ & $58,34 \pm 0,58^{*}$ \\
\hline
\end{tabular}

Примечание. * - статистически значимые $(p \leqslant 0,05)$ различия между животными, получавшими ВН и препарат адеметионин с протекторной активностью и животными, получавшими только ВН.

Note. ${ }^{*}$ - statistically significant $(p \leqslant 0.05)$ differences between animals treated with sodium valproate and the drug ademetionine with protective activity and animals treated only with sodium valproate.

Таблица 3/Table 3

Концентрации ДК, МДА, GSH и активность ГР, ГТ, ГПО в печени крыс, подвергнутых воздействию ВН и препарата коррекции цитофлавина, $(M \pm m)$

Concentrations of DC, MDA, and GSH and activities of GR, GT, and GPO in the liver of rats exposed to the toxic effect of SV and the corrective treatment with citoflavin

\begin{tabular}{|c|c|c|c|c|c|c|c|c|}
\hline \multirow[b]{3}{*}{ Показатели } & \multicolumn{8}{|c|}{ Сроки исследования (сутки) } \\
\hline & \multicolumn{2}{|c|}{7 сут } & \multicolumn{2}{|c|}{14 сут } & \multicolumn{2}{|c|}{21 сут } & \multicolumn{2}{|c|}{28 сут } \\
\hline & $\begin{array}{c}\text { Группа 2-я } \\
\text { (контроль) } \\
n=23\end{array}$ & $\begin{array}{c}\text { Группа 4-я } \\
\text { (опыт) } \\
n=11\end{array}$ & $\begin{array}{c}\text { Группа 2-я } \\
\text { (контроль) } \\
n=13\end{array}$ & $\begin{array}{c}\text { Группа 4-я } \\
\text { (опыт) } \\
n=12\end{array}$ & $\begin{array}{c}\text { Группа 2-я } \\
\text { (контроль) } \\
n=13\end{array}$ & $\begin{array}{c}\text { Группа } 4 \\
\text { (опыт) } \\
n=13\end{array}$ & $\begin{array}{c}\text { Группа } 2 \\
\text { (контроль } \\
n=15 \\
\end{array}$ & $\begin{array}{c}\text { Группа } 4 \\
\text { (опыт) } \\
n=12\end{array}$ \\
\hline ДК, мКмоль/мл & $10,81 \pm 0,33$ & $9,52 \pm 0,04 *$ & $14,91 \pm 0,36$ & $12,83 \pm 0,13^{*}$ & $17,22 \pm 0,51$ & $15,52 \pm 0,79$ & $29,32 \pm 0,52$ & $21,31 \pm 0,09^{*}$ \\
\hline $\begin{array}{l}\text { МДА, } \\
\text { мКмоль/мл }\end{array}$ & $8,32 \pm 0,31$ & $7,31 \pm 0,02 *$ & $8,32 \pm 0,20$ & $6,71 \pm 0,11^{*}$ & $14,51 \pm 0,47$ & $8,41 \pm 0,10^{*}$ & $17,51 \pm 0,48$ & $7,13 \pm 0,04^{*}$ \\
\hline $\begin{array}{l}\text { ГР, нмоль/мин } \\
\text { на } 1 \text { мг белка }\end{array}$ & $17,23 \pm 0,86$ & $29,42 \pm 0,52^{*}$ & $29,33 \pm 0,65$ & $29,12 \pm 0,43$ & $13,52 \pm 0,57$ & $27,81 \pm 0,29^{*}$ & $15,81 \pm 0,62$ & $27,81 \pm 0,09^{*}$ \\
\hline $\begin{array}{l}\text { ГТ, нмоль/мин } \\
\text { на } 1 \text { мг белка }\end{array}$ & $308,21 \pm 10,54$ & $317,22 \pm 6,54$ & $223,12 \pm 7,82$ & $272,13 \pm 3,84^{*}$ & $250,11 \pm 8,03$ & $311,23 \pm 2,91^{*}$ & $249,23 \pm 5,41$ & $347,14 \pm 5,98^{*}$ \\
\hline $\begin{array}{l}\text { ГПО, нмоль/мин } \\
\text { на } 1 \text { мг белка }\end{array}$ & $86,11 \pm 0,98$ & $63,42 \pm 1,39^{*}$ & $98,23 \pm 6,83$ & $61,14 \pm 1,06^{*}$ & $82,11 \pm 5,93$ & $59,33 \pm 0,49^{*}$ & $154,21 \pm 7,21$ & $70,32 \pm 0,75^{*}$ \\
\hline
\end{tabular}

Примечание. * - статистически значимые различия $(p \leqslant 0,05)$ между животными, получавшими ВН и препарат цитофлавин с протекторной активностью и животными, получавшими только ВН.

Note. ${ }^{*}$ - statistically significant differences $(p \leqslant 0.05)$ between animals receiving sodium valproate and the drug cytoflavin with protective activity and animals receiving only sodium valproate. 


\section{Обсуждение}

Согласно полученным данным введение крысам больших доз ВН вызывает значительные изменения в системе ПОЛ-АОЗ ткани печени, что выражается в накоплении продуктов пероксидации и резком снижении активности ферментов системы глутатиона в гепатоцитах. Это может быть связано как с прямым поражением клеток одним из токсичных метаболитов ВН - пропиленовой кислотой, так и опосредованным влиянием ВН, который подавляет синтез и активность ферментов дыхательной цепи, угнетает $\beta$-окисление жирных кислот в митохондриях гепатоцитов, активирует апоптозные каспазы [14]. Одновременно, при хронической передозировке ВН снижается уровень L-карнитина, что приводит к накоплению жирных кислот в цитоплазме гепатоцитов, уменьшению содержания глутатиона [15-17].

Выявленный нами протекторный эффект адеметионина может быть обусловлен его регуляторным влиянием на процессы роста и дифференцировки гепатоцитов, он является главным донором метила и, таким образом, восстанавливает запасы глутатиона в печени в эксперименте [18-20]. Защитное действие цитофлавина, которое мы регистрировали у крыс с интоксикацией ВН, скорее всего связано с неспецифическим влиянием этого препарата на биоэнергетику клетки, которое приводит к восстановлению активности ферментов антиоксидантной защиты, уменьшению продукции свободных радикалов, повышает активность ГПО и ГТ [21]. Установлено, что дигидрокверцетин проявляет незначительный антиоксидантный эффект у крыс с передозировкой ВН. Имеются данные о том, что дигидрокверцетин уменьшает расходование витамина Е, оказывает синергическое действие в отношении аскорбиновой кислоты, способствует уменьшению повреждающего действия пероксида [22, 23].

\section{Заключение}

Проведенные исследования показали, что ВН в токсической дозе приводит к статистически значимому повышению продуктов ПОЛ и снижению антиокислительной защиты (АО3) в печени. Адеметионин, цитофлавин и дигидрокверцетин способствуют восстановлению баланса системы ПОЛ-АОЗ в печени крыс и могут использоваться в качестве гепатопротекторов при передозировке ВН. По нашему мнению, наиболее перспективным препаратом защиты является адеметионин, так как он более значительно снижает концентрацию ДК, МДА и повышает активность системы глутатиона на протяжении 28 сут.

Таблича 4/Table 4

\section{Концентрации ДК, МДА, GSH и активность ГР, ГТ, ГПО в печени крыс, подвергнутых воздействию ВН} и препарата коррекции дигидрокверцетина, $(M \pm m)$

Concentrations of DC, MDA, and GSH and activities of GR, GT, and GPO in the liver of rats exposed to the toxic effect of SV and the corrective treatment with dihydroquercetin

\begin{tabular}{|c|c|c|c|c|c|c|c|c|}
\hline \multirow[b]{3}{*}{ Показатели } & \multicolumn{8}{|c|}{ Сроки исследования (сутки) } \\
\hline & \multicolumn{2}{|c|}{7 сут } & \multicolumn{2}{|c|}{14 сут } & \multicolumn{2}{|c|}{21 сут } & \multicolumn{2}{|c|}{28 сут } \\
\hline & $\begin{array}{c}\text { Группа 2 } \\
\text { (контроль) } \\
n=23\end{array}$ & $\begin{array}{c}\text { Группа } 5 \\
\text { (опытн) } \\
n=11\end{array}$ & $\begin{array}{c}\text { Группа } 2 \\
\text { (контроль) } \\
n=13\end{array}$ & $\begin{array}{c}\text { Группа } 5 \\
\text { (опыт) } \\
n=10\end{array}$ & $\begin{array}{c}\text { Группа } 2 \\
\text { (контроль) } \\
n=13\end{array}$ & $\begin{array}{c}\text { Группа } 5 \\
\text { (опыт) } \\
n=12\end{array}$ & $\begin{array}{c}\text { Группа } 2 \\
\text { (контроль) } \\
n=15\end{array}$ & $\begin{array}{c}\text { Группа } 5 \\
\text { (опыт) } \\
n=12\end{array}$ \\
\hline ДК, мКмоль/мл & $10,81 \pm 0,33$ & $10,52 \pm 0,15$ & $14,91 \pm 0,36$ & $13,22 \pm 0,29^{*}$ & $17,22 \pm 0,51$ & $15,22 \pm 0,13^{*}$ & $29,32 \pm 0,52$ & $19,22 \pm 0,05^{*}$ \\
\hline GSH, мкмоль/г & $5,41 \pm 0,06$ & $4,33 \pm 0,09^{*}$ & $4,51 \pm 0,26$ & $4,33 \pm 0,12$ & $4,53 \pm 0,26$ & $5,13 \pm 0,02^{*}$ & $4,63 \pm 0,19$ & $3,74 \pm 0,04 *$ \\
\hline $\begin{array}{l}\text { ГР, нмоль/мин } \\
\text { на } 1 \text { мг белка }\end{array}$ & $17,23 \pm 0,86$ & $24,21 \pm 0,02^{*}$ & $29,33 \pm 0,65$ & $24,41 \pm 0,46^{*}$ & $13,52 \pm 0,57$ & $24,13 \pm 0,39^{*}$ & $15,81 \pm 0,62$ & $22,12 \pm 0,16^{*}$ \\
\hline $\begin{array}{l}\text { ГТ, нмоль/мин } \\
\text { на } 1 \text { мг белка }\end{array}$ & $308,21 \pm 10,54$ & $147,22 \pm 2,07 *$ & $223,12 \pm 7,82$ & $287,23 \pm 4,59 *$ & $250,11 \pm 8,03$ & $275,23 \pm 4,48^{*}$ & $249,23 \pm 5,41$ & $281,22 \pm 2,20^{*}$ \\
\hline $\begin{array}{l}\text { ГПО, нмоль/мин } \\
\text { на } 1 \text { мг белка }\end{array}$ & $86,11 \pm 0,98$ & $56,23 \pm 0,47^{*}$ & $98,23 \pm 6,83$ & $56,32 \pm 0,55^{*}$ & $82,11 \pm 5,93$ & $57,31 \pm 0,35^{*}$ & $154,21 \pm 7,21$ & $57,82 \pm 0,21 *$ \\
\hline
\end{tabular}

Примечание. * - статистически значимые различия $(p \leqslant 0,05)$ между животными, получавшими ВН и препарат дигидрокверцетин с протекторной активностью и животными, получавшими только ВН.

Note. * statistically significant differences $(p \leqslant 0.05)$ between animals receiving sodium valproate and the drug dihydroquercetin with protective activity and animals receiving only sodium valproate. 


\section{DOI: 10.25557/0031-2991.2021.03.56-63}

\section{Литература (п.п. 3; 6; 13; 16; 17; 19; 20; 23 см. References)}

1. Логинов А.Ф., Буторова Л.И., Логинов В.А. Лекарственные поражения печени: диагностика, лечение. РМЖ. 2016; 11: 721-7.

2. Ивашкин В.Т., Барановский А.Ю., Райхельсон К.Л., Пальгова Л.К., Маевская М.В., Кондрашина Э.А., и др. Лекарственные поражения печени (клинические рекомендации для врачей). Российский журнал гастроэнтерологии, гепатологии, колопроктологии. 2019; 29(1): 101-31.

4. Власов П.Н., Орехова Н.В., Антонюк М.В., Филатова Н.В., Шнайдер Н.А., Дмитренко Д.В. и др. Эффективность и безопасность препаратов вальпроевой кислоты с контролируемым высвобождением активного вещества у взрослых в реальной клинической практике с позиции фармакокинетического и фармакогенетического подхода. Неврология, нейропсихиатрия, психосоматика. 2017; 51: 11-20.

5. Пылаева О.А., Мухин К.Ю., Петрухин А.С., ред. Побочные эффекты антиэпилептической терапии. М.: ГРАНАТ; 2016.

7. Охремчук Л.В., Семинский И.Ж. Закономерности нарушения поведенческой активности беспородных крыс при токсическом воздействии вальпроата натрия (сообщение 1). ЭНИ Забайкальский медицинский вестник. 2018; 4: 35-47.

8. Семинский И.Ж., Охремчук Л.В. Протекторный эффект адеметионина, цитофлавина, дигидрокверцетина при нарушении поведенческой активности беспородных крыс подвергнутых воздействию вальпроата натрия в токсической дозе (сообщение 2). ЭНИ Забайкальский медицинский вестник. 2018; 4: 48-63.

9. Белоусов Ю.Б., Кукес В.Г., Лепахин В.К., Петрова В.И., ред. Клиническая фармакология: национальное руководство. М.: ГЭОТАР-Медиа; 2014.

10. Гаврилов В.Б., Мишкорудная М.И. Спектрофотометрическое определение содержания гидроперекисей липидов в плазме крови. Лабораторное дело. 1983; 3: 23-5.

11. Стальная И.Д., Граишвили Т.Г. Метод определения малонового диальдегида. М.: Медицина; 1977.

12. Колесниченко Л.С., Кулинский В.И., Сотникова Г.В., Ковтун В.Ю. Влияние направленного изменения концентрации глутатиона на температуру тела и толерантность к ишемии головного мозга. Биохимия. 2003; 68(5): 656-63.

14. Шнайдер Н.А., Дмитренко Д.В. Хроническая интоксикация вальпроевой кислотой в эпилептологии: диагностика и лечение. Неврология, Нейропсихиатрия, Психосоматика. 2016; 8(2): 94-9.

15. Малеев В.В., Ситников И.Г., Бохонов М.С. Вопросы гепатологии. Учебное пособие. Санкт-Петербург; 2016.

18. Силивончик Н.Н., Адаменко Е.И., Богуш Л.С. Адеметионин: физиологические эффекты и применение в лечении заболеваний печени. Международные обзоры: клиническая практика и здоровье. 2017; 2(25): 33-49.

21. Доровских В.А., Симонова Н.В., Переверзев Д.И., Штарберг М.А. Сравнительная эффективность цитофлавина и его составных компонентов при окислительном стрессе в эксперименте. Экспериментальная и клиническая фармакология. 2017; 80(4): 18-22.

22. Роговский В.С. Антигипертензивная и нейропротекторная активность кверцетина и его производных. Экспериментальная и клиническая фармакология. 2012; 75(9): 37-41.

\section{References}

1. Loginov A.F., Butorova L.I., Loginov V.A. Drug-induced liver injury: diagnosis and treatment. RMJ. Gastroenterology. 2016; 11: 72127. (in Russian)

2. Ivashkin V.T., Baranovsky A.Yu., Raikhelson K.L., Palgova L.K., Maevskaya M.V., Kondrashina E.A., et al. Drug-Induced Liver Injuries (Clinical Guidelines for Physicians). Rus J Gastroenterol Hepatol Coloproctol. 2019; 29(1): 101-31. (In Russian)

3. Bunchorntavakul C., Reddy K.R. Reviewarticle: herbal and dietary supplement hepatotoxicity. Aliment Pharmacol Ther. 2013; 37(1): 3-17.

4. Vlasov P.N., Orekhova M.V., Filatova N.V., Schnaider Dmitrenko D.V., Zobova S.N., Poverennova I.E., et al. The efficacy and safety of valproic acid medications with controlled active ingredient release in adults in real clinical practice from the position of pharmacokinetic and pharmacogenetic approaches. Nevrologiya, neyropsikhiatriya, psikhosomatika. 2017; 51: 11-20. (In Russian)

5. Pylaeva O.A., Mukhin K. Yu., Petrukhin A.S., eds. Side effects of antiepileptic medication. Pobochnye effekty antiepilepticheskoj terapii. [Pobochnye effekty antiepilepticheskoy terapii]. Moscow; Granat; 2016. (In Russian)

6. Nevitt S.J., Sudell M., Weston J., Tudur Smith C., Marson A.G. Antiepileptic drug monotherapy for epilepsy: a network metaanalysis of individual participant data. Cochrane Database Syst. Rev. 2017; Jun (6): $572-73$.

7. Okhremchuk L.V., SeminskyI. Zh. Regularities of the impaired behavior alactivity in mongrel rats under the toxic effects of sodium valproate (report 1). Zabaykal'skiy meditsinskiy vestnik. 2018; 4: 35-47. (In Russian)

8. Seminsky I.Zh., Okhremchuk L.V. The protective effect of ademetionine, cytoflavinum, dihydroquercetin in the violation of behavioral activty in mongrel rats exposed to sodium valproate at a toxic dose (report № 2). Zabaykal'skiy meditsinskiy vestnik. 2018; 4: 48-63. (In Russian)

9. Belousov Yu.B., Kukes V.G., Lepakhin V.K., Petrov V.I., ed. Clinical pharmacology: national guidelines. [Klinicheskaya farmakologiya: natsional'noe rukovodstvo]. Moscow: GEOTAR-media; 2014. (In Russian)

10. Gavrilov V.B., Mishkorudnaya M.I. Spectrophotometric determination of lipid hydroperoxides in blood plasma. Laboratory business. 1983; 3: 23-5. (In Russian)

11. Stalnaya I.D., Garishvili T.G. Method for the determination of malondialdehyde. [Metod opredeleniya malonovogo dial'degida]. Moscow: Meditsina; 1977. (In Russian)

12. Kolesnichenko L.S., Kulinsky V.I., Sotnikova G.V., Kovtun V.Yu. The influence of purposeful changes of glutathione concentration on body temperature and the tolerance to cerebral ischemia. Biokhimiya. 2003; 68(5): 656-63. (In Russian)

13. Anderson M.E. Enzymatic and chemical methods for the determination of glutathione. N.Y; 1989: 339-66.

14. Shnaider N.A., Dmitrenko D.V. Chronic valproic acid intoxication in epileptology: diagnosis and treatment. Nevrologiya, neyropsikhiatriya, psikhosomatika. 2016; 8(2): 94-9. (In Russian)

15. Maleyev V.V., Sitnikov I.G., Bokhonov M.S. Questions of hepatology. Training manual. [Voprosy gepatologii. Uchebnoye posobiye]. SanktPeterburg; 2016. (In Russian)

16. Delemos A.S., Foureau D.M., Jacobs C., Ahrens W., Russo M.W., Bonkovsky H.L. Drug-induced liver injury with autoimmune features. Semin Liver Dis. 2014; 34(2): 194-204. 
17. Ortega-Alonso A., Stephens C., Lucena M.I., Andrade R.J. Case character-ization, clinical featuresandriskfactorsindrug inducedliverinjury. Int Mol Sci. 2016; 17(5): 714.

18. Silivontchik N.N., Adamenka A.I., Bogush L.S. Ademetionine: physiological effects and use in treatment of liver diseases. Mezhdunarodnye obzory: klinicheskaya praktika i zdorov'e. 2017; 2(25): 33-49. (In Russian)

19. Mato J.M., Martinez-Chantar M.L., Lu S.C. S-adenosylmethionine metabolism and liver disease. Ann Hepatol. 2013; 12: 183-9.

20. Lu S.C., Mato J.M. S-adenosylmethionine in liver health, injury, and cancer. Physiol Rev. 2012; 92: 1515-42.
21. Dorovskikh V.A., Simonova N.V., Pereverzev D.I., Shtarberg M.A. Comparative effectiveness of cytoflavin and its constituent components in experimental oxidative stress. Eksperimental'naya $i$ klinicheskaya farmakologiya. 2017; 80(4): 18-22. (In Russian)

22. Rogovskii V.S., Shimanovskii N.L., Matyushin A.I. Antihypertensive and Neuroprotective Activity of Quercetin and Its Derivatives. Eksperimental'nayai klinicheskaya farmakologiya.2012; 75(9): 37-41. (In Russian)

23. Rogovsky V.S., Rosenfeld M.A., Leonova V.B., Konstantinova M.L., Razumovsky S.D., Matyoshin A.I., et al. Dihydroquercetin Inhibits Ozone Oxidation of Fibrinogen. New Steps in Physical Chemistry, Chemical Physics and Biochemical Physics. 2012; March: 151-58.

\section{Сведения об авторах:}

Охремчук Людмила Васильевна, канд. мед. наук, доцент каф. патологической физиологии и клинической лабораторной диагностики ФГБОУ ВО ИГМУ Минздрава России, е-mail: doktor777030371@gmail.com;

Семинский Игорь Жанович, доктор мед. наук, проф., зав. каф. патологической физиологии и клинической лабораторной диагностики ФГБОУ ВО ИГМУ Минздрава России. 